\title{
ВОЗМОЖНОСТЬ ПРИМЕНЕНИЯ ВОЛНОВЫХ ИНФОРМАЦИОННЫХ ОБРАЗОВ МЕДИКАМЕНТОВ ДЛЯ КОНТРОЛЯ И ПЕРЕДАЧИ ВОЗДЕЙСТВИЙ 1
}

\section{POSSIBILITY OF APPLICATION OF WAVE INFORMATION IMAGES OF MEDICINES FOR CONTROL AND TRANSMISSION OF EFFECTS}

\section{O. Vasiliev \\ Yu. Voitenko \\ V. Zhevnerov}

Summary. The features of the spectra of information images of various medicines and the possibility of their use for organizing the process of managing the current state of the human body have been investigated. For the formation and recording of information images of medicines on LEDs, specialized certified electromagnetic devices were used. The experiments have shown the possibility of reliable recognition of medicines based on the spectral analysis of information images and the detection of signs of the impact of the transferred information images of medicines on the human body. The identity of the impact of information images and originals of medicines was confirmed. The possibility of a significant increase in the working capacity of the human body by the proposed non-doping technology is shown. The use of wave information images is very promising for the construction of control systems and correction of the psychophysical state of the human body.

Keywords: information, informational image, working capacity, LEDs, spiral antennas, electromagnetic radiation.

$\Pi$ од информационным образом вещества понимается структура его собственного сверхслабого электромагнитного излучения, определяющая основные свойства этого вещества. В настоящее время изучению особенностей регистрации и передачи информационных образов для организации определённых воздействий уделяется достаточно заметное внимание [1]. В ряде работ такие воздействия относят к классу не-
Васильев Олег Станиславович

К.n.н., дочент, Российский государственный университет физической культуры и спорта vasilev.os@yandex.ru

Войтенко Юрий Леонидович К.n.н., доцент, Российский государственный университет физической культуры и спорта yuravoitenko2014@yandex.ru

Жевнеров Владимир Алексеевич

K.т.н., дочент, Российский университет дружбы народов

jewn@mail.ru

Аннотация. Исследованы особенности спектров информационных образов различных медикаментов и возможность их использования для организации процесса управления текущим состоянием организма человека. Для формирования и записи информационных образов медикаментов на светодиоды применялись специализированные сертифицированные электромагнитные устройства. Проведенные эксперименты показали возможность достоверного распознавания медикаментов на основе спектрального анализа информационных образов и обнаружения признаков воздействия переносимых информационных образов медикаментов на человеческий организм. Подтверждена идентичность оказываемого воздействия информационных образов и оригиналов медикаментов. Показана возможность существенного повышения работоспособности организма человека предлагаемой недопинговой технологией. Применение волновых информационных образов является весьма перспективным для построения систем контроля и коррекции психофизического состояния организма человека.

Ключевые слова: информация, информационный образ, работоспособность, светодиоды, спиральные антенны, электромагнитное излучение.

локальных взаимодействий [2]. Основные известные исследования в этом направлении проводятся в области биологии, медицины и разработки устройств регистрации и переноса информационных образов веществ [3-4].

Основные результаты экспериментов по регистрации, записи и переносу информационных образов различных веществ приведены в [5]. 


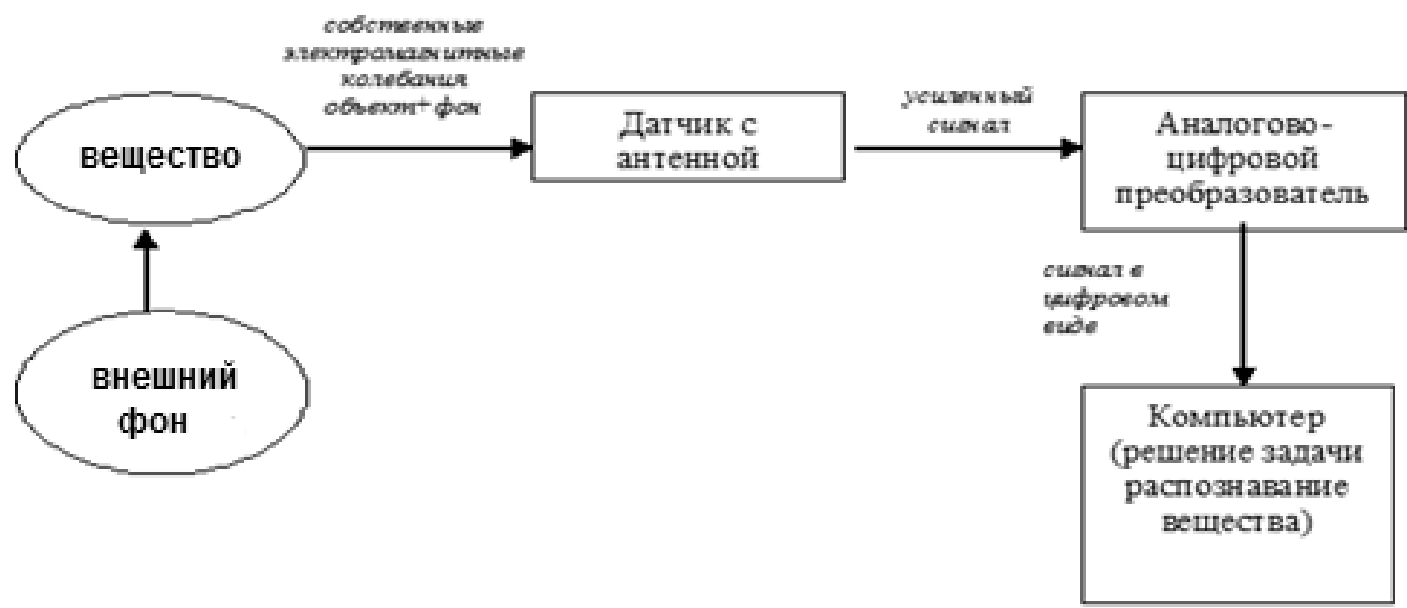

Рис. 1. Обобщённая структура системы записи и распознавания информационных образов

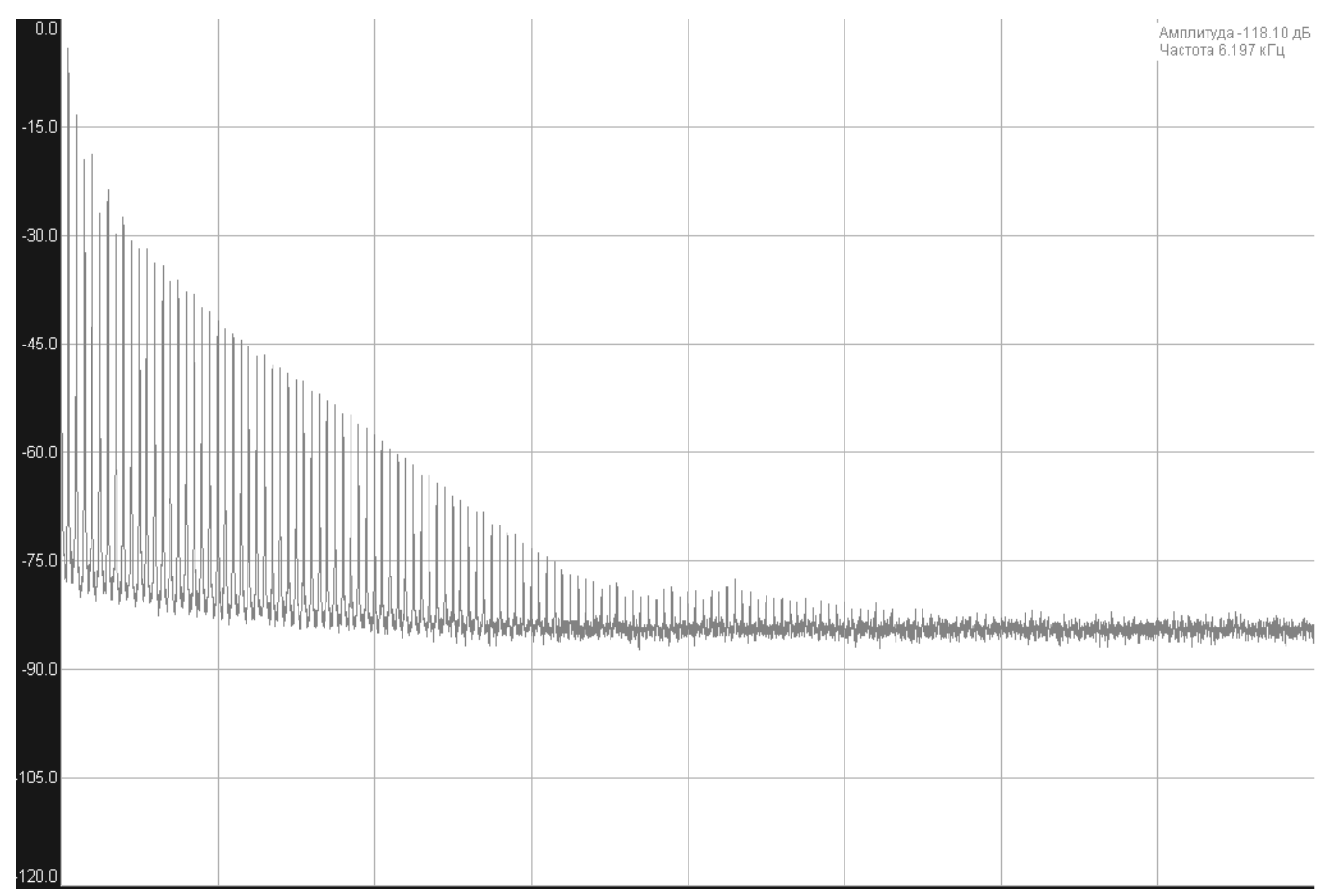

Рис. 2. Спектр исходной воды

Для регистрации, усиления и передачи информационных образов различных веществ применялись оригинальные электромагнитные устройства серии «Феникс-М» [6]. Устройства предназначены для приёма и записи собственных электромагнитных излучений различных веществ. Структура системы записи информационных образов и распознавания по ним наличия конкретных веществ в обобщённом виде представлена на рис. 1.

Сигнал с выхода датчика поступает на аналогово-цифровой преобразователь и записывается в базу данных компьютера. Распознавание информационных образов предлагается производить стандартными методами спектрального анализа.

Запись информационного образа на носитель производится усиленным сигналом, поступающим на передающую антенну, рядом с которой размещается носитель [5].

В начале исследований производилась запись информационных образов различных медикаментов 


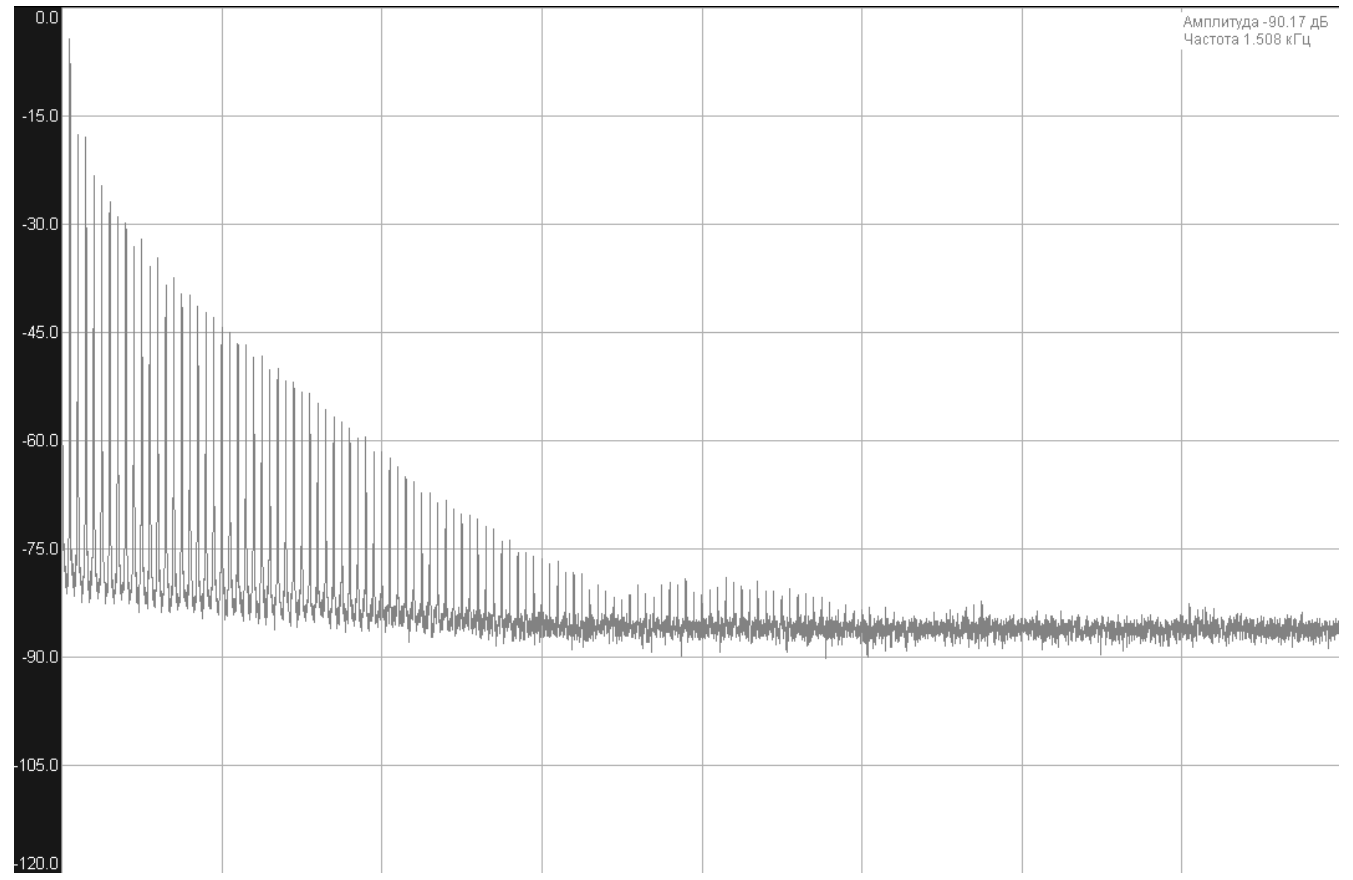

Рис. 3. Спектр воды с викардином

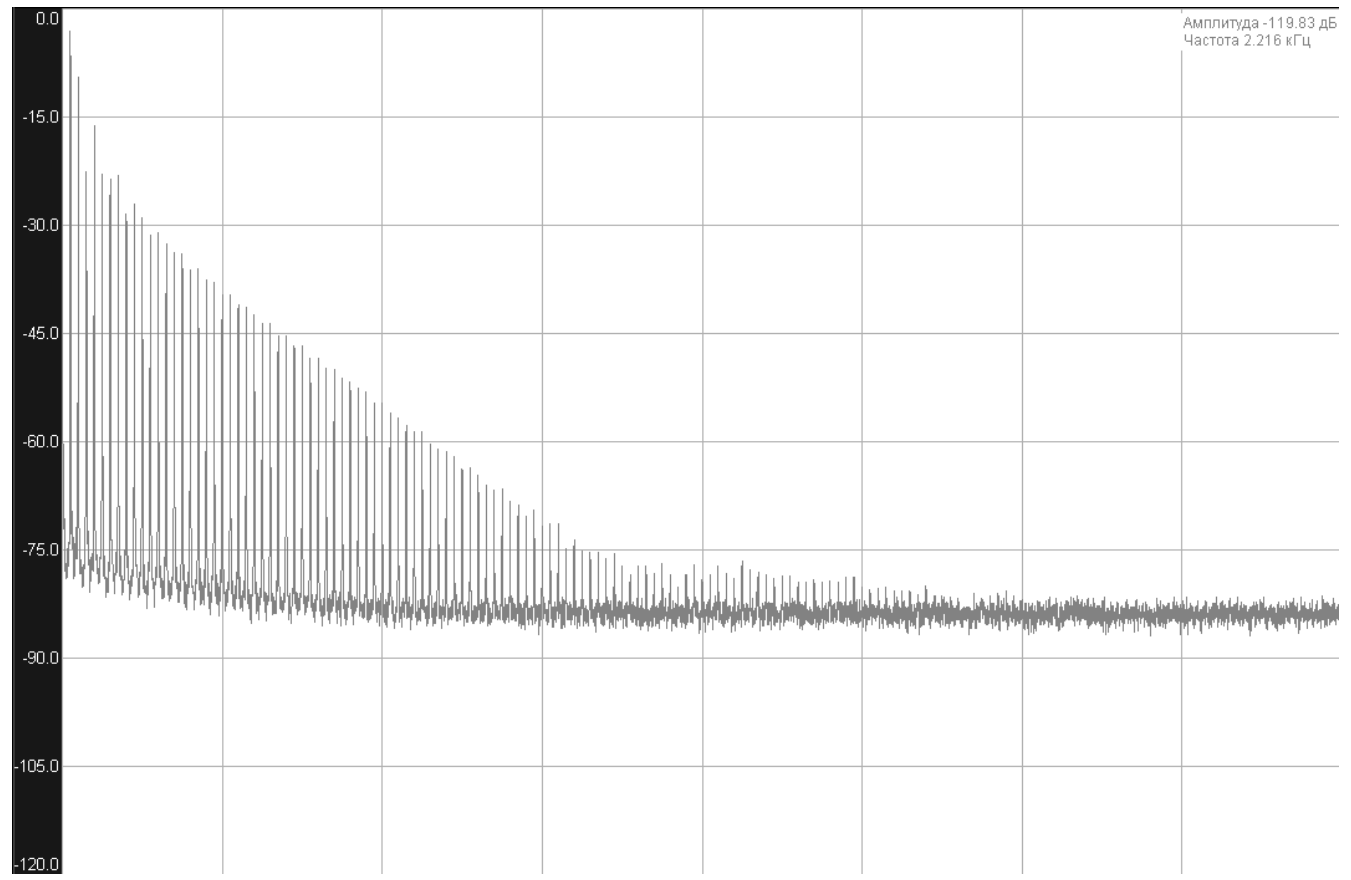

Рис. 4. Спектр воды с винейроном

на воду. В качестве типичного примера на рис. 2-5 приведены спектры воды в начальном состоянии и после записи на воду информационных образов растворов следующих тканеспецифических адгезивных факторов:

Викардин - ткани сердца;

Винейрон - ткани мозга;

Випульмин - ткани лёгких.
Спектры приведены для частот в диапазоне $0 \div 8$ кГц. Масштаб 1,0 кГц/деление.

Концентрация растворов этих веществ составляет достаточно малую величину - 10-6. Это делает невозможным проведение стандартными методами анализа присутствия веществ в растворе. 


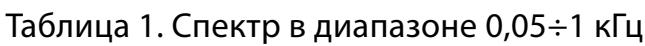

\begin{tabular}{|l|l|}
\hline Наводимое вещество & Код \\
\hline Чистая вода & 1001010100100010000 \\
\hline Викардин & 1000000001010100000 \\
\hline Винейрон & 1001001010010010100 \\
\hline Випульмин & 1001001001010000010 \\
\hline
\end{tabular}

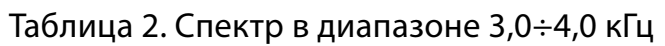

\begin{tabular}{|l|l|}
\hline Наводимое вещество & Код \\
\hline Чистая вода & 10000010001101010110 \\
\hline Викардин & 10100001000110011010 \\
\hline Винейрон & 11101000010011010011 \\
\hline Випульмин & 11000100110101010101 \\
\hline
\end{tabular}

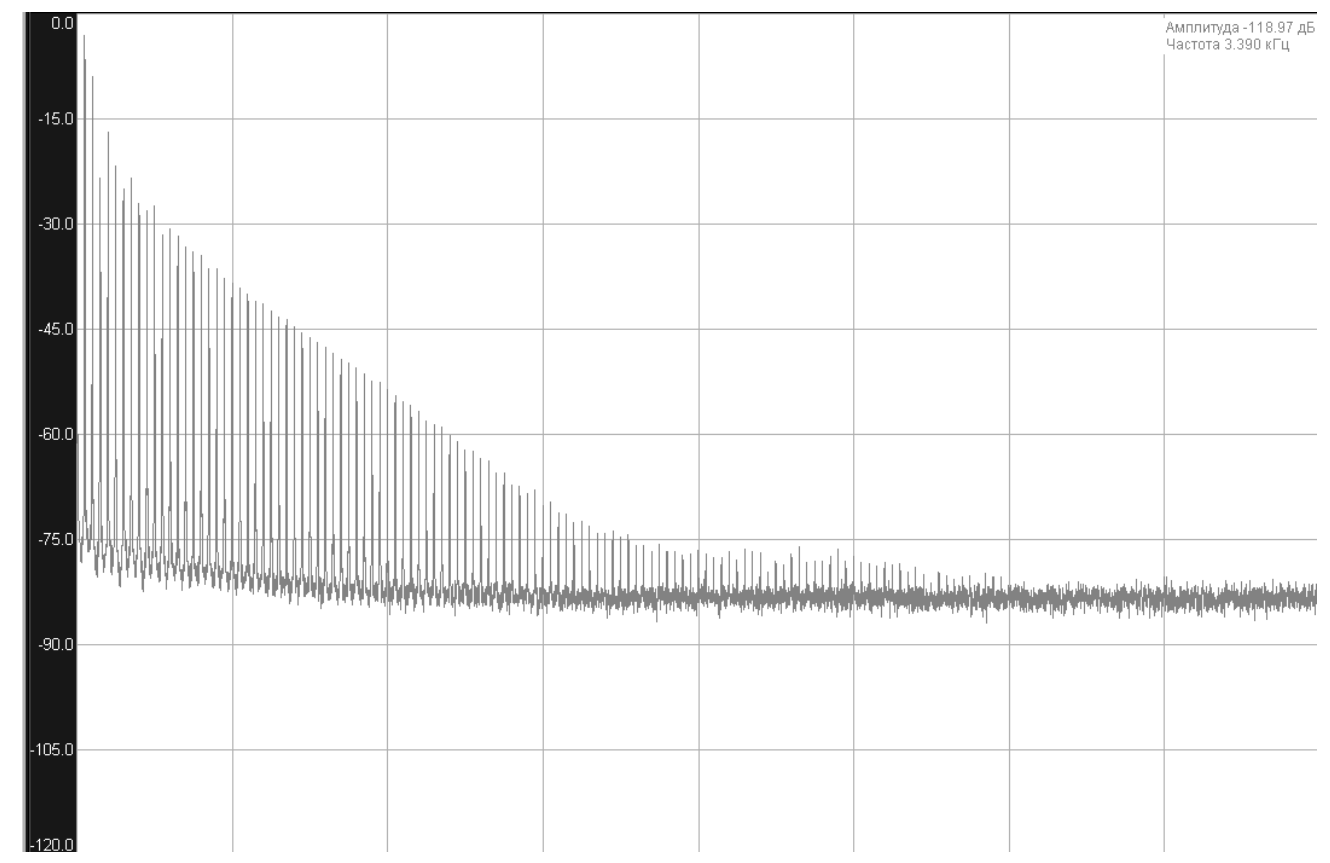

Рис. 5. Спектр воды с випульмином

В спектрах явно наблюдается наличие гармоник 50-герцового фона.

Проведенный анализ показал, что наиболее простым и достаточно достоверным является распознавание наличия определённых веществ по их простейшим кодам, образуемых по следующему принципу:

- учитываются только значения спектров в точках $50^{*} \mathrm{n}, \mathrm{n}=1,2,3, \ldots$;

- кодом вещества является последовательность $\left\{a_{n}\right\} ;$

- $\mathrm{a}_{1}=1, \mathrm{a}_{\mathrm{n}}=1$, если амплитуда в точке $\mathrm{n}$ выше, чем в точке $\mathrm{n}-1$, в противном случае $a_{n}=0$.
Примеры таких кодов приведены в табл. $1 \div 3$ для разных частотных диапазонов.

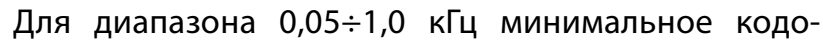
вое расстояние (количество несовпадающих позиций, табл. 1) равно 4, что достаточно для достоверного распознавания даже для такого самого примитивного принципа кодирования - без учёта амплитуды спектра, а только по принципу «больше-меньше».

Для более высокочастотной части спектра различие увеличивается, поэтому распознавание будет ещё

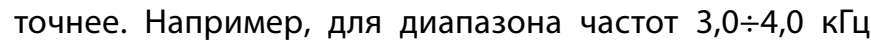


Таблица 3. Формула крови до и после воздействия

\begin{tabular}{|l|l|}
\hline начальное состояние & после 10 минутного воздействия \\
Возраст:23 Вес:85 Частота дых:14 Пульс:58 & 1. Гемоглобин: 179,54 г/л \\
\hline 1. Гемоглобин: 138,27 г/л & 2. Эритроциты: 5,36 \\
2. Эритроциты: 4,41 & 3. СОЭ: 10,73 мм/час \\
3. СОЭ: 7,83 мм/час & 4. Лимфоциты: $15,34 \%$ \\
4. Лимфоциты: $35,18 \%$ & 5. Лейкоциты: 10,98 \\
5. Лейкоциты: 7,78 & \\
\hline
\end{tabular}

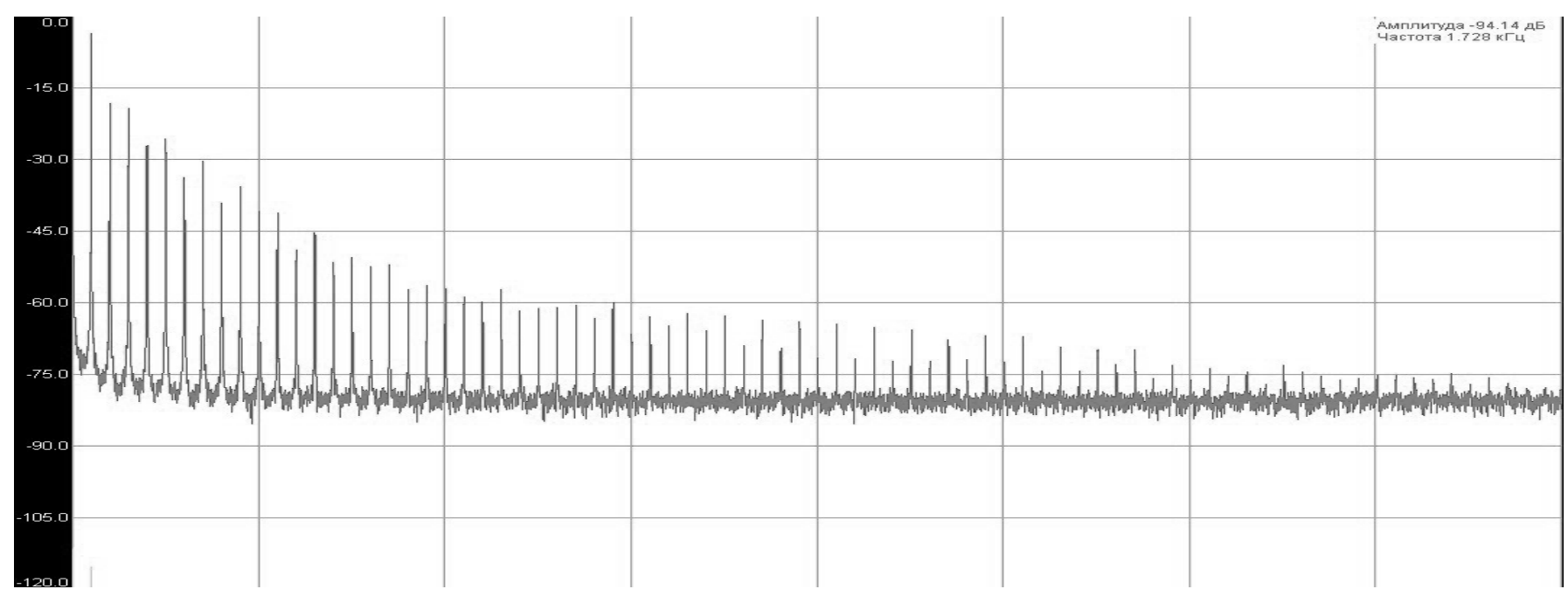

Рис. 6. Исходное состояние

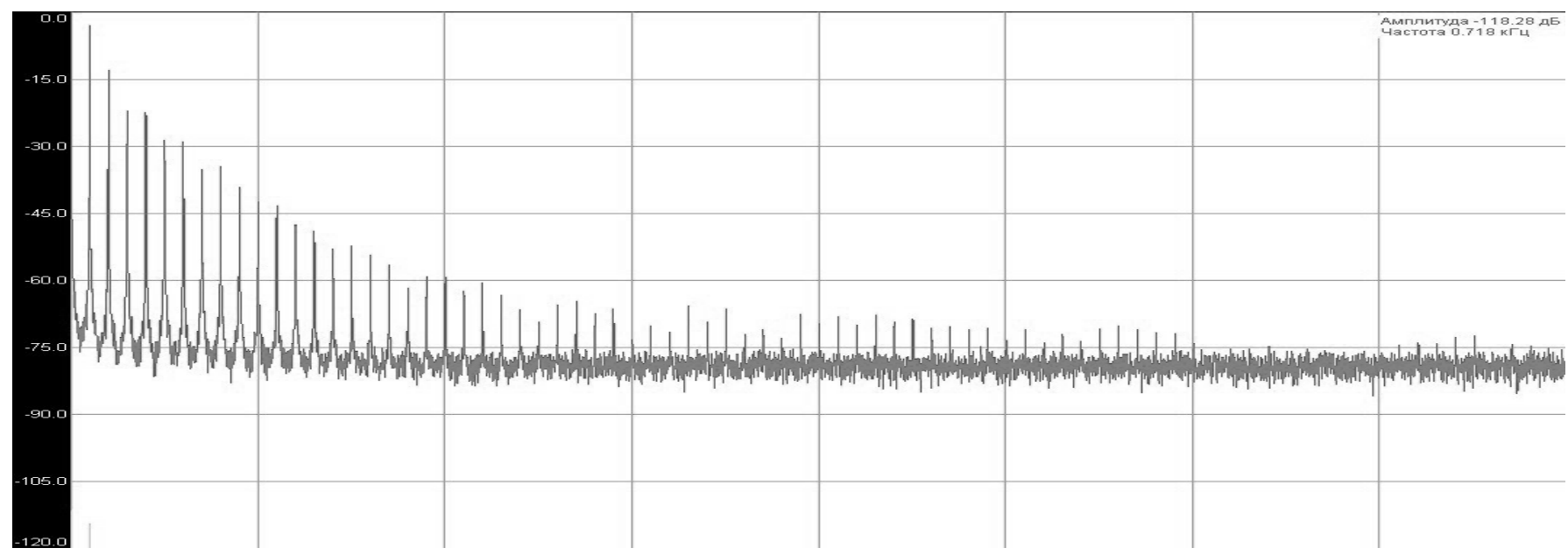

Рис. 7. Воздействие мелатонина

(Табл. 2) минимальное кодовое расстояние будет равно уже 6.

В последующих опытах исследовалось влияние на воду в стакане излучения руки человека, находящегося в различных состояниях. На рис. $5 \div 6$ приведены типичные результаты эксперимента для испытуемого в текущем состоянии и после 5-минутного сеанса воздействия мелатонином, вызывающего релаксацию организма. Спектры сигналов приведены в масштабе 0,5 кГц/деление в диапазоне $0 \div 4$ кГц. 
Достоверным признаком появления релаксации организма после воздействия мелатонина является отсутствие заметных пиков сигнала в 7 делении (диапазон частот $3,0 \div 3,5$ кГц).

В дальнейших исследованиях информационные образы медикаментов записывались на светодиод. Далее производилось облучение включённым светодиодом определённых участком кожи волонтёров.

Типичный пример изменения биохимического состава крови в результате 10-минутного воздействия информационного образа АТФ, записанного на светодиод, на спортсмена высшей квалификации (единоборец, чемпион Европы), приведен в. Табл. 3. В результате воздействия произошло повышение уровня гемоглобина на 41 г/л, то есть на $30 \%$. Это означает соответствующий прирост энергоресурсов, что настоящее время является лучшим из известных результатов.

\section{Выво $\Delta$}

1. Проведенные эксперименты с различными видами медикаментов подтвердили существование их информационных образов, оказывающих воздействие на организм человека, аналогичное оригиналу.

2. Показана возможность достаточно достоверного распознавания веществ по спектру их информационных образов.

3. Установлена принципиальная возможность контроля состояния организма человека по изменению спектра его собственного электромагнитного излучения.

4. Предлагаемый подход позволяет обеспечить существенное повышение работоспособности не допинговыми средствами и является весьма перспективным для применения в терапии и спортивной медицине.

\section{ЛИТЕРАТУРА}

1. J. Benveniste; P. Jurgens; W. Hsueh; J. Aissa (21-26 February 1997). «Transatlantic Transfer of Digitized Antigen Signal by Telephone Link». Journal of Allergy and Clinical Immunology. 99 (1): S175. doi:10.1016/S0091-6749(97)81064-0.

2. Р.Ш. Саркисян, Г.Г. Карамян, А.М. Манукян, А.Г. Никогосян, В.Т. Варданян. Дистанционные нелокальные взаимодействия в биологических, химических и физических системах // Журнал Формирующихся Направлений Науки, № 7(3), стр. 12-33, 2015

3. А. Менегетти. Психосоматика. ННБФ“Онтопсихология", М., 2005. 360 с.

4. Жевнеров В.А. Способ регистрации ЭМИ биологических объектов//Научные перспективы XXI века. Достижения и перспективы нового столетия, —-2015, № 2(9) Часть 4, с. 16-19

5. Жевнеров В.А. Мещеряков А.В., Боген М.М. и др. «Практическое применение дистанционного воздействия на функциональные резервы человека при помощи передачи информации, записанной на светодиоды», Образование и Право, № 11, 2019, с. 178-184

6. Шовкопляс Ю.А., Жевнеров В., Гукасов В.М. Профилактика и коррекция утомления, как основа эффективной человеческой деятельности. Система мониторинга и коррекции уровней утомления человека // Медицина и высокие технологии. 2016. № 2. С. 45-54.

(c) Васильев Олег Станиславович ( vasilev.os@yandex.ru ),

Войтенко Юрий Леонидович ( yuravoitenko2014@yandex.ru ), Жевнеров Владимир Алексеевич ( jewn@mail.ru ).

Журнал «Современная наука: актуальные проблемы теории и практики» 